\title{
Differentiation of Epithelial cells to M Cells in Response to Bacterial Colonization on the Follicle-Associated Epithelium of Peyer's Patch in Rat Small Intestine
}

\author{
Keigi CHIN ${ }^{1}$, Sachiko ONISHI ${ }^{1}$, Midori YUJI ${ }^{1)}$, Tetsurou INAMOTO ${ }^{1}$, Wang-Mei QI ${ }^{1}$, Katsuhiko WARITA ${ }^{1)}$, \\ Toshifumi YOKOYAMA ${ }^{2)}$, Nobuhiko HOSHI ${ }^{1)}$ and Hiroshi KITAGAWA ${ }^{1) *}$ \\ ${ }^{1)}$ Department of Bioresource and Agrobiosciences, Graduate School of Science and Technology, Kobe University, Kobe 657-8501 and \\ ${ }^{2}$ Department of Anatomy and Neurobiology, Faculty of Medicine, Kagawa University, Kagawa 761-0793, Japan
}

(Received 13 January 2006/Accepted 8 May 2006)

ABSTRACT. To clarify the relationship between $\mathrm{M}$ cells and intestinal microflora, histoplanimetrical investigation into the bacterial colonization and the differentiation to $\mathrm{M}$ cells was carried out in rat Peyer's patch under physiological conditions. The follicle-associated epithelium (FAE), except for the narrow area of apical region, was closely covered with both neighboring intestinal villi and a thick mucous layer, the latter of which also filled the intervillous spaces as well as the space between the FAE and the neighboring intestinal villi. Indigenous bacteria adhered almost constantly to the narrow areas of apical regions of both intestinal villi and the FAE. Bacterial colonies were occasionally located on the basal to middle region of FAE, where M cells also appeared, forming large pockets. When bacterial colonies were located on the basal to middle region of FAE, bacteria with the same morphological characteristics also proliferated in the intervillous spaces neighboring the Peyer's patch. In cases with no bacterial colonies on the basal to middle region of FAE, however, M cells were rare in the FAE. Histoplanimetrical analysis showed the similar distribution pattern of bacterial colonies on the FAE and M cells in the FAE. M cells ultrastructurally engulfed indigenous bacteria, which were then transported to the pockets. These results suggest that indigenous bacterial colonization on the FAE stimulates the differentiation of M cells in the FAE under physiological conditions. The uptake of bacteria by $\mathrm{M}$ cells might contribute the regulation of the development of indigenous bacterial colonies in the small intestine.

KEY WORDS: bacterial colonization, cellular differentiation, M cell, microflora, Peyer's patch of rat.

J. Vet. Med. Sci. 68(10): 1023-1028, 2006

The formation of intestinal microflora begins at birth in animals. The residence of the microflora provides various benefits to the host, such as exclusion of pathogenic bacteria, production of short-chain fatty acids, synthesis of essential nutrients such as certain vitamins, and assistance with oral tolerance $[4,26]$. On the other hand, intestinal microflora have been suggested to be essential in driving the inflammatory process in human inflammatory bowel diseases, and they have been reported to play a part in the initiation of colonic cancer [9]. The composition of intestinal microflora is almost stable, although it may transiently vary under some pathological conditions or an influence of antibacterial agents [9]. Many studies analyzing bacterial numbers or species along the gastrointestinal tract have been conducted in various animal species (for review, see Kararli [14]). In human, the number of bacteria in the proximal small intestine is $10^{0-5} / \mathrm{g}$ and increases toward the large intestine, finally reaching $10^{10-11} /$ $\mathrm{g}$ in rectum or feces [14]. Numerous defensive factors have been hypothesized to be involved in maintaining constant numbers and a balance of intestinal microflora. Defects in these factors may allow the bacterial overgrowth in intestines [4]. However, the colonization site and its mechanisms of intestinal microflora in vivo are still unclear.

Luminal information is sampled by $\mathrm{M}$ cells in the follicleassociated epithelium (FAE) on mucosa-associated

\footnotetext{
* Correspondence to: Kitagawa, H., Graduate School of Science and Technology, Kobe University, Kobe 657-8501, Japan.
}

lymphoid tissues [8]. Many researchers have experimentally demonstrated the ability of $\mathrm{M}$ cells to take up various kinds of soluble or solid tracers and microorganisms [8]. M cells are used not only for sampling and for transporting luminal antigens, but also for exploring undesirable pathways for invasion of some pathogenic microorganisms $[2,13]$. However, whether or not $\mathrm{M}$ cells uptake and transport indigenous bacteria has never been clarified in physiological conditions. In this study, we examined the adhering sites of indigenous bacteria in rat Peyer's patch and its neighboring intestinal villi by light and electron microscopy. To clarify the responsibility of epithelial cells in the FAE to indigenous bacteria adhesion in rat Peyer's patch, we also histoplanimetrically examined the distributions of $\mathrm{M}$ cells in the FAE and of bacterial colonies on the FAE.

\section{MATERIALS AND METHODS}

Animals: A total of 20 male Wistar rats aged $6-7$ weeks (SLC Inc., Japan) were used according to the guidelines for the care and use of experimental animals on the Rokkodai Campus of Kobe University. They were allowed free access to commercial compound feed (Labo MR Stock; Nosan Corporation, Japan) and water. The animal facility was maintained on conditions of a $12 \mathrm{hr}$ light/dark cycle, at $21 \pm$ $1^{\circ} \mathrm{C}$ and $50-60 \%$ humidity. Clinical and pathological examinations confirmed that none of the animals had any sign of a disorder. 
Light microscopy: Fifteen animals were killed by cardiac exsanguination under anesthesia by inhalation of ethyl ether. Peyer's patches were extracted quickly from the lower jejunum and ileum, and immersion-fixed in cold Bouin's fixative for $24 \mathrm{hr}$ at $4^{\circ} \mathrm{C}$. The blocks were then dehydrated and embedded in paraffin. Serial paraffin sections, $4 \mu \mathrm{m}$ thick, were stained with hematoxylin and eosin. A total of 60 lymphoid follicles were observed under light microscope.

Quantitative histology: Five follicles were randomly chosen from 45 follicles colonized by indigenous bacteria on their basal to middle FAE.
The distributions of $M$ cells with typical pockets in the FAE and bacterial colonies in the FAE were light microscopically measured using a $100 \times$ objective lens. In brief, the length from the crypt orifice to the apex of the FAE was represented as $100 \%$. The numbers of $\mathrm{M}$ cells in each $10 \%$ length of the FAE were counted individually. In each $5 \%$ length of FAE, each bacterial colony was counted as 1 point. Finally, the distribution of each of these factors was represented by the average number of 5 domes in each $10 \%$ length. The distribution center of each factor was represented as the average lengths from the crypt orifice in the 5 domes.
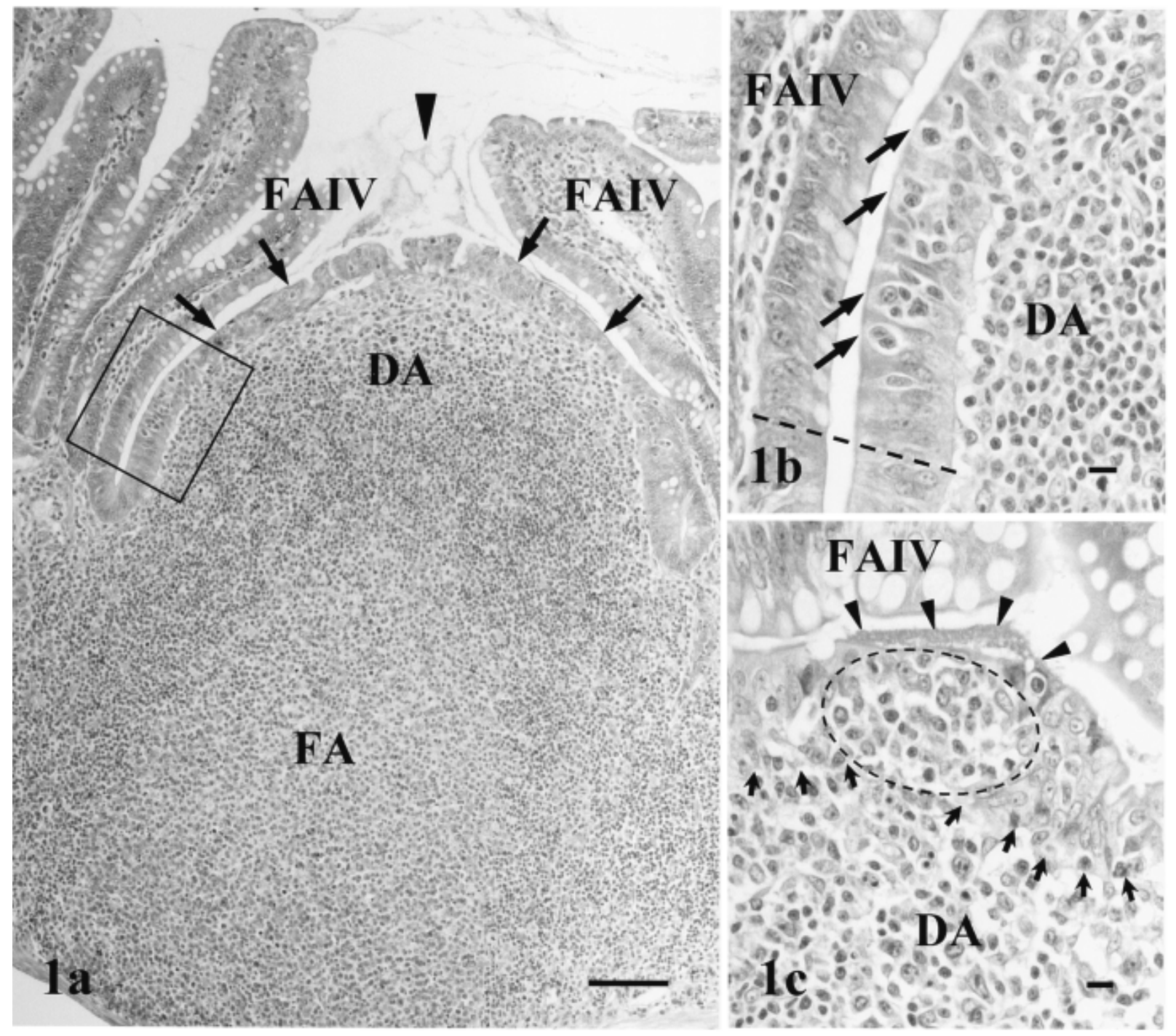

Fig. 1a-c. a) The dome area in the Peyer's patch is embedded among the intestinal villi. FAE (arrows) is covered with follicle-associated intestinal villi (FAIV) except for its narrow apical area. The narrow space on the apical region of the FAE is filled with thick mucus (arrowhead). b) High magnification of a square in Fig. 1a. M cells (arrows) are located near the crypt orifice (dotted line). c) A bacterial colony (arrowheads) adheres to the FAE surface. In the FAE just beneath the bacterial colony, M cells form a large pocket, where numerous migrating cells including macrophages-like cells are harbored (dotted circle). Arrows indicate the basal membrane of FAE. The size of the large pocket should be compared with the ordinary pockets of single M cells (arrows) in Fig. 1b. DA, dome area; FA, follicular area. Bar $=10 \mu \mathrm{m}$. 
Transmission electron microscopy: After euthanasia, 5 animals were perfused with $2.5 \%$ glutaraldehyde $-2.0 \%$ paraformaldehyde in $0.1 \mathrm{M}$ phosphate buffer ( $\mathrm{PB}, \mathrm{pH} 7.4)$ and immersion-fixed in the same fixative for $22 \mathrm{hr}$ at $4^{\circ} \mathrm{C}$. After postfixation with $1.0 \% \mathrm{OsO}_{4}$ in $0.1 \mathrm{M} \mathrm{PB}$ for $2 \mathrm{hr}$ at room temperature, the specimens were embedded in a Quetol 812 mixture. Ultrathin sections contrasted with both uranyl acetate and lead citrate were observed under a transmission electron microscope (Hitachi H-7100, Japan) at an accelerating voltage of $75 \mathrm{kV}$.

\section{RESULTS}

General structure: Each follicle in a Peyer's patch was composed of the FAE, a dome area, a follicular area and a parafollicular area. The FAE was tightly covered with follicle-associated intestinal villi except for the narrow areas of apical regoins. The FAE never reached the stream of luminal contents, because the domes were lower than intestinal villi. A thick mucus layer always covered on the apices and filled the narrow spaces between the FAE and follicle-associated intestinal villi or the narrow intervillous spaces (Fig. 1a).

In general, the FAE consisted of predominant microvillous columnar epithelial cells, a few $\mathrm{M}$ cells and goblet cells. Apoptotic epithelial cells, such as chromatincondensed and cytoplasm-shrunk cells were frequently observed in the apical region and scarcely in the middle and basal regions of the FAE.

Distribution of $M$ cells: $M$ cells were dispersed in the FAE except for the narrow area of apical region. Typical M cell was characterized by the dome-shaped form, the few microvilli and the pocket which harbored many intraepithelial migrating cells. M cells appeared first near the crypt orifice of the FAE (Fig. 1b). When M cells lined up in the FAE continuously, pockets of $\mathrm{M}$ cells combined together to form a single large pocket (Fig. 1c). M cells were located predominantly in FAE's lower half and decreased in number toward its apex. The distribution center of M cells was $41.0 \pm 22.1 \%$ of the length of the FAE from the crypt orifices (Fig. 2a).

The migrating cells including macrophage-like cells often accumulated in the pockets of $\mathrm{M}$ cells and formed clusters in the lamina propria beneath the M cells (Fig. 1c). The macrophage-like cells were characterized by the large and clear nucleus, and the elongated cytoplasm which contained some acidophilic lysosomes and cell debris. The macrophage-like cells were also densely populated in the apical dome area beneath the FAE.

Distribution of bacterial colonies: Unlike heterogeneous populations of bacteria with different morphologies in the intestinal luminal contents, homogeneous populations with the same morphologies colonized on the FAE and intestinal villi in many cases. Indigenous bacteria were almost constantly adhered to the narrow areas of apical regions of both FAE and intestinal villi. In this case, apoptotic signs and the protrusion of exfoliating epithelial cells were
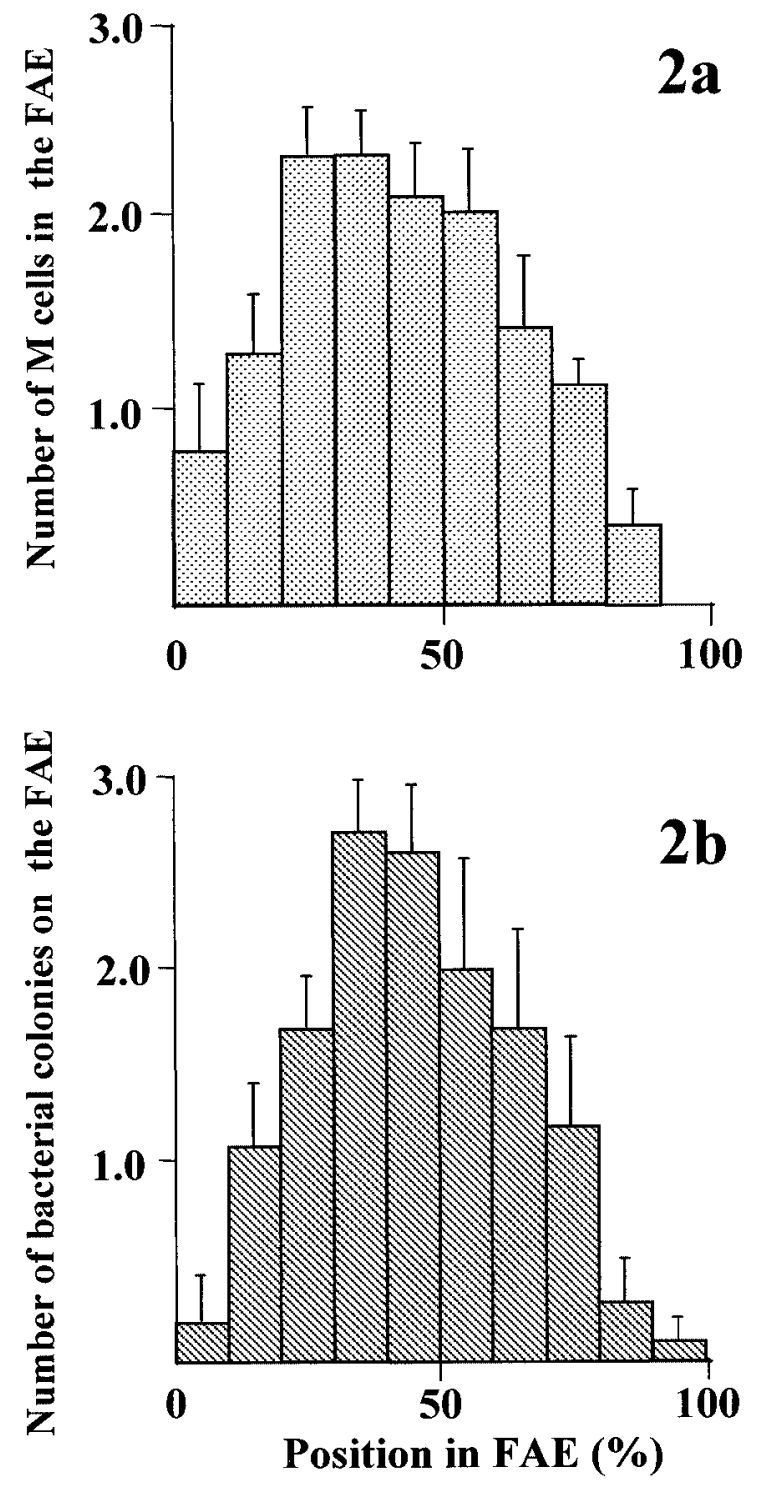

Fig. 2ab. a) Distribution of $M$ cells in the FAE. b) Distribution of bacterial colonies on the FAE of Peyer's patch. The length from crypt orifice to apex of the FAE represented $100 \%$ at the FAE length. The numbers of $\mathrm{M}$ cells and bacterial colonies in each $10 \%$ of FAE length are shown. Each value represents mean \pm S.E. of 5 follicles.

observed more frequently at the apices of the FAE and intestinal villi than in the case that indigenous bacteria were rarely seen at the apical regions (Fig. 3a). Some bacteria also fell into the lumen with the apoptotic epithelial cells. Occasionally, bacterial colonies were located on the middle to basal regions of the FAE. In these cases, $M$ cells appeared in the portions of the FAE adjacent to bacterial colonies (Fig. 3b). The distribution pattern of the $\mathrm{M}$ cells in FAE was extremely similar to that of bacterial colonies on the FAE (Fig. 2b). When bacterial colonies existed on the 

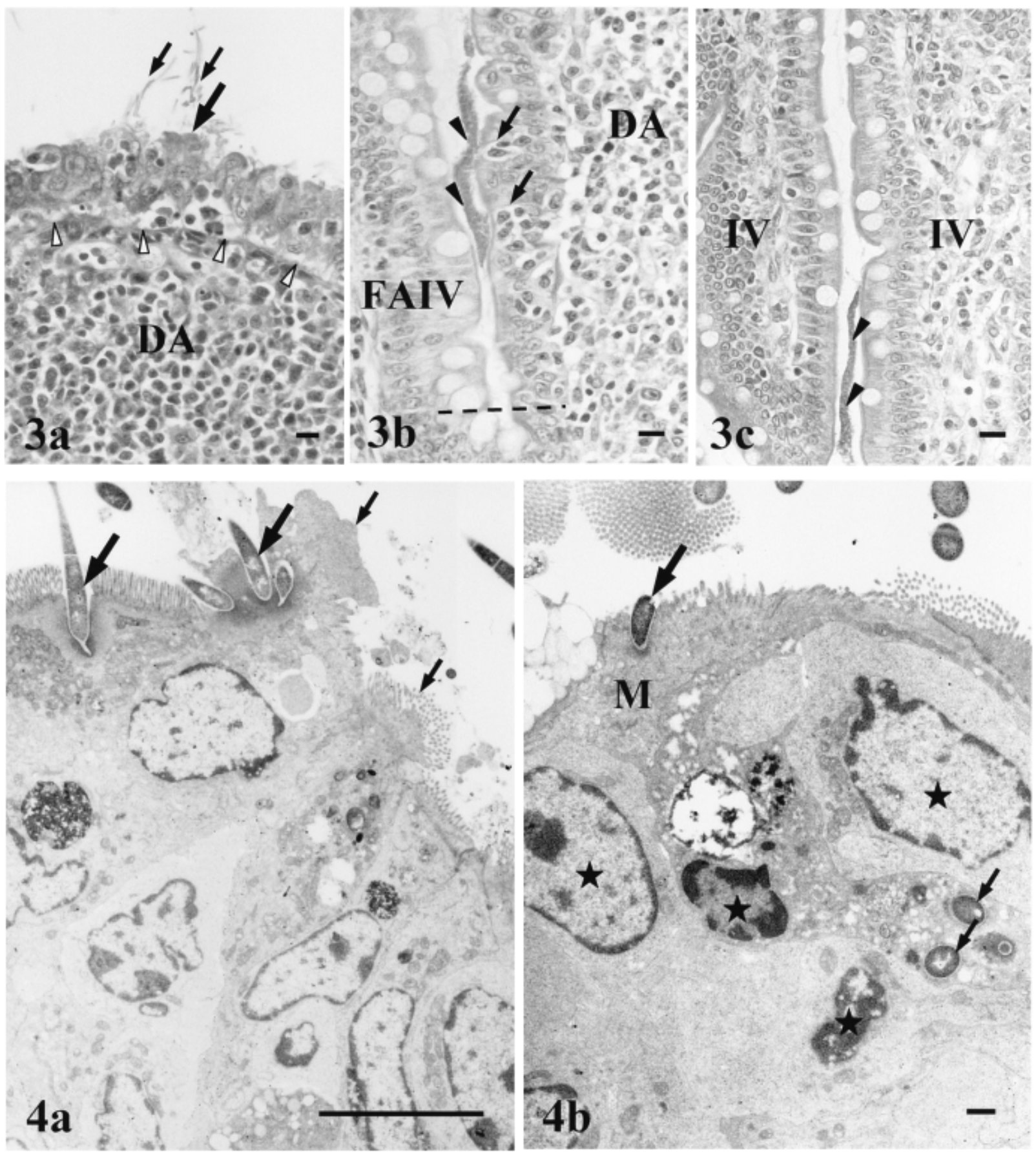

Fig. 3a-c. a) Indigenous bacteria with filamentous form (small arrows) adhere to the apex of the FAE. Accumulation of exfoliating epithelial cells slightly protrudes into intestinal lumen (large arrow). No M cells appear at the adhesion site of the bacteria. White arrowheads indicate the basement membrane of FAE. b) A colony (arrowheads) of bacteria with fine spherical form adheres to the FAE locating close to the crypt orifice (dotted line). M cells with marked pockets (arrows) are located in the FAE just beneath the bacterial colony. c) A bacterial colony (arrowheads) adheres to the basal region of intestinal villous space near the Peyer's patch. The bacteria are the same fine sphere as in Fig. 3b. DA, dome area; follicle-associated intestinal villus, FAIV; IV, intestinal villi. Bar=10 $\mu \mathrm{m}$.

Fig. 4ab. a) Electron micrograph of an apex of FAE. A number of bacteria tightly adhere to the epithelial cells (large arrows). The adhesion sites are surrounded by electron-dense materials in the epithelial cells. Exfoliating epithelial cells protrude into the lumen (small arrows). Bar $=10 \mu \mathrm{m} . \mathrm{b}$ ) Electron micrograph of an $\mathrm{M}$ cell (M) in the basal region of the FAE. A bacterium adheres to the apical surface of an M cell membrane (large arrow). Beneath the flattened cytoplasm of $\mathrm{M}$ cell, many migrating cells (asterisks) are located in the pocket. Bacteria are also visible in the migrating cells in the pocket of $\mathrm{M}$ cells (small arrows). Bar $=1 \mu \mathrm{m}$. 
basal to middle region of FAE, the bacteria with the same morphological characteristics were also located in deep intervillous spaces near the Peyer's patch (Fig. 3c). The distribution center of the bacterial colonies was $45.8 \pm$ $22.5 \%$ of the FAE from the orifice of the intestinal crypt (Fig. 3c). In cases that there were no bacterial colonies on the basal to middle region of FAE, M cells appeared poorly in the FAE.

Ultrastructure of FAE: In the narrow area of apical region of the FAE, indigenous bacteria adhered constantly and tightly to form invaginations of cell membranes of microvillous epithelial cells. The invaginations were surrounded by electron-dense materials beneath the cell membranes of epithelial cells, which often protruded into the lumen (Fig. 4a). On the other hand, few morphological changes were observed in the adhesion site of $\mathrm{M}$ cells in the basal to middle region of the FAE. The indigenous bacteria engulfed by $M$ cells were located in the migrating cells of the pockets (Fig. 4b).

\section{DISCUSSION}

In this study, the narrow areas of apical regions of the FAE and intestinal villi are an almost constant adhering site of indigenous bacteria exclusively. The apices of both FAE and intestinal villi are also important sites of epithelial exfoliation $[10,15,28]$. In germ-free animals, the transit time of epithelial cells migrating toward the tips of intestinal villi is prolonged [29], and the renewal of epithelium is markedly retarded [1]. In the present study, the formation of clusters of exfoliating epithelial cells suggests the acceleration of the apoptotic process in epithelial cells colonized by indigenous bacteria. Therefore, the colonization of indigenous bacteria might be maintained by the balance of both the elimination of bacteria with shedding of apoptotic epithelial cells and the bacterial proliferation rate.

$\mathrm{M}$ cells are predominantly distributed in the basal to middle regions, rather than apical regions of the FAE in Peyer's patches of rabbit [12], mouse [21], human [19], cecal patches of rabbit $[11,12]$ and cecal tonsils of chicken [15]. Almost all of the FAE were covered with adjacent mucosa in human Peyer's patches and rabbit appendix [17, 19]. We demonstrated that the rat FAE except for the narrow area of apical region, was covered with the adjacent intestinal villi. Moreover, the narrow spaces between the FAE and adjacent villi were filled with a thick mucus. M cells were also predominant in the lower half of the FAE and sparse in the apical areas of the Peyer's patch. These results suggest that most $M$ cells are away from the stream of luminal contents and that the situation of M cells in the FAE is unsuitable for constant monitoring of luminal food antigens under physiological conditions in animals.

Peyer's patches are less developed in germ-free animals than in conventional animals [18, 20]. The conventionalization of SPF mice causes a threefold increase in the number of M cells in the FAEs of Peyer's patches
[22]. Moreover, the injection of Salmonella pneumoniae to the artificial intestinal loops of germ-free rabbits markedly increases in the number of $\mathrm{M}$ cells that are restricted to the periphery, though no such increases in $\mathrm{M}$ cells are found in the apical region of the FAE [5]. The present study demonstrated that the appearance of $\mathrm{M}$ cells was closely correlated with bacterial colonization in the FAE. This result suggests that the cellular differentiation of $M$ cells corresponds with the bacterial colonization on the FAE of Peyer's patches.

The nonspecific defense factors against bacteria include gastrointestinal motility, gastric acid, antibacterial substances of biliary and pancreatic secretions, thick mucus layer, Paneth cells and so on [4]. A natural antibody, which is thought to be produced by B1 cells without the T-cell activation process [16], may also play an important role in host defense against a wide spectrum of microorganisms [6]. Activation of some of these factors has been reported after the exposure to microorganisms. Namely, Paneth cells secrete granule contents in mouse small intestinal crypts when the mucous membrane is exposed to bacteria or bacterial antigens [3]. In germ-free mice, single colonization of segmented filamentous bacteria, a nonpathogenic anaerobic bacteria, leads to a strong increase in the number of IgA-secreting cells in the small intestine [25]. However, no concrete mechanisms of the induction of antibacterial factors have been suggested in the regulation of microflora in vivo. The present morphological and histoplanimetrical data showed that the appearance of $\mathrm{M}$ cells depended on the bacterial colonization on the FAE of Peyer's patches. Moreover, the present ultrastructural investigation suggests the uptake and transcytosis of indigenous bacteria in $\mathrm{M}$ cells. These findings might indicate that the pathway via $\mathrm{M}$ cells delivers information on indigenous bacteria to intestinal host defense mechanisms, thereby allowing the regulation of bacterial colonization.

There are two hypotheses about the cellular origin of $\mathrm{M}$ cells. One is that $\mathrm{M}$ cells differentiate from matured epithelial cells $[23,24]$, and the other is that M cells directly differentiate from immature epithelial cells [7, 15, 27]. The latter thus far has predominated. In this study, many mature $M$ cells appeared in the FAE immediately above the crypt orifices. Moreover, the distribution of $\mathrm{M}$ cells in the FAE was reduced toward the apices, where no $\mathrm{M}$ cells existed. Therefore, we reconfirm the direct differentiation of $\mathrm{M}$ cells from immature epithelial cells at the basal region of the FAE. On the other hand, our study also showed a close relationship between the appearance of $M$ cells in the middle region of the FAE and bacterial colonization on the FAE. This finding also might indicate that $\mathrm{M}$ cells are partially differentiated from the immature epithelial cells which migrate into the middle region of FAE, in response to the stimulation of colonization of indigenous bacteria that proliferate in deep mucosa.

ACKNOWLEDGMENT. This work was financially 
supported in part by a Grant-in-Aid for Scientific Research (no. 16580239) from the Japan Society for the Promotion of Science.

\section{REFERENCES}

1. Abrams, G. D., Bauer, H. and Sprinz, H. 1963. Influence of the normal flora on mucosal morphology and cellular renewal in the ileum. A comparison of germ-free and conventional mice. Lab. Invest. 12: 355-363.

2. Amerongen, H. M., Weltzin, R., Farnet, C. M., Michetti, P., Haseltine, W. A. and Neutra, M. R. 1991. Transepithelial transport of HIV-1 by intestinal M cells: a mechanism for transmission of AIDS. J. Acquir. Immune Defic. Syndr. 4: 760765.

3. Ayabe, T., Satchell, D. P., Wilson, C. L., Parks, W. C., Selsted, M. E. and Ouellette, A. J. 2000. Secretion of microbicidal $\alpha$-defensins by intestinal Paneth cells in response to bacteria. Nat. Immunol. 1: 113-118.

4. Batt, R. M., Rutgers, H. C. and Sancak, A. A. 1996. Enteric bacteria: friend or foe? J. Small Anim. Pract. 37: 261-267.

5. Borghesi, C., Taussing, M. J. and Nicoletti, C. 1999. Rapid appearance of $\mathrm{M}$ cells after microbial challenge is restricted at the periphery of the follicle-associated epithelium of Peyer's patch. Lab. Invest. 79: 1393-1401.

6. Coutinho, A., Kazatchkine, M. D. and Avrameas, S. 1995. Natural autoantibodies. Curr. Opin. Immunol. 7: 812-818.

7. Gebert, A., Fassbender, S., Werner, K. and Weissferdt, A. 1999. The development of M cells in Peyer's patches is restricted to specialized dome-associated crypts. Am. J. Pathol. 154: $1573-1582$.

8. Gebert, A., Rothkötter, H. J. and Pabst, R. 1996. M cells in Peyer's patches of the intestine. Int. Rev. Cytol. 167: 91-159.

9. Guarner, F. and Malagelada, J. R. 2003. Gut flora in health and disease. Lancet 361: 512-519.

10. Iwanaga, T. 1995. The involvement of macrophages and lymphocytes in the apoptosis of enterocytes. Arch. Histol. Cytol. 58: 151-159.

11. Jepson, M. A., Clark, M. A., Simmons, N. L. and Hirst, B. H. 1993. Epithelial M cells in the rabbit caecal lymphoid patch display distinctive surface characteristics. Histochemistry 100: 441-447.

12. Jepson, M. A., Simmons, N. L., Hirst, G. L. and Hirst, B. H. 1993. Identification of $\mathrm{M}$ cells and their distribution in rabbit intestinal Peyer's patches and appendix. Cell Tissue Res. 273: $127-136$

13. Jones, B., Pascopella, L. and Falkow, S. 1995. Entry of microbes into the host: using M cells to break the mucosal barrier. Curr. Opin. Immunol. 7: 474-478.

14. Kararli, T. T. 1995. Comparison of the gastrointestinal anatomy, physiology, and biochemistry of humans and commonly used laboratory animals. Biopharm. Drug Dispos. 16: $351-380$

15. Kitagawa, H., Hosokawa, M., Takeuchi, T., Yokoyama, T.,
Imagawa, T. and Uehara, M. 2003. The cellular differentiation of $\mathrm{M}$ cells from crypt undifferentiated epithelial cells into microvillous epithelial cells in follicle-associated epithelia of chicken cecal tonsils. J. Vet. Med. Sci. 65: 171-178.

16. Macpherson, A. J., Gatto, D., Sainsbury, E., Harriman, G. R., Hengartner, H. and Zinkernagel, R. M. 2000. A primitive T cell-independent mechanism of intestinal mucosal IgA responses to commensal bacteria. Science 288: 2222-2226.

17. Marchetti, M., Sirard, J. C., Sansonetti, P., Pringault, E. and Kerneis, S. 2004. Interaction of pathogenic bacteria with rabbit appendix M cells: bacterial motility is a key feature in vivo. Microbes Infect. 6: 521-528.

18. Nagura, H. 1992. Mucosal defense mechanism in health and disease. Role of the mucosal immune system. Acta Pathol. Jpn. 42: 387-400.

19. Owen, R. L. and Jones, A. L. 1974. Epithelial cell specialization within human Peyer's patches: an ultrastructural study of intestinal lymphoid follicles. Gastroenterology 66: 189-203.

20. Pollard, M. and Sharon, N. 1970. Responses of the Peyer's patches in germ-free mice to antigenic stimulation. Infect. Immun. 2: 96-100.

21. Savidge, T. C., Smith, M. W., James, P. S. and Aldred, P. 1991. Salmonella-induced M-cell formation in germ-free mouse Peyer's patch tissue. Am. J. Pathol. 139: 177-184.

22. Smith, M. W., James, P. S. and Tivey, D. R. 1989. M cell numbers increase after transfer of SPF mice to a normal animal house environment. Am. J. Pathol. 128: 385-389.

23. Smith, M. W. and Peacock, M. A. 1980. 'M" cell distribution in follicle-associated epithelium of mouse Peyer's patch. Am. J. Anat. 159: 167-175.

24. Smith, M. W. and Peacock, M. A. 1992. Microvillus growth and M-cell formation in mouse Peyer's patch follicleassociated epithelial tissue. Exp. Physiol. 77: 389-392.

25. Snel, J., Hermsen, C. C., Smits, H. J., Bos, N. A., Eling, W. M., Cebra, J. J. and Heidt, P. J. 1998. Interactions between gutassociated lymphoid tissue and colonization levels of indigenous, segmented, filamentous bacteria in the small intestine of mice. Can. J. Microbiol. 44: 1177-1182.

26. Sudo, N., Sawamura, S., Tanaka, K., Aiba, Y., Kubo, C. and Koga, Y. 1997. The requirement of intestinal bacterial flora for the development of an IgE production system fully susceptible to oral tolerance induction. J. Immunol. 159: 1739-1745.

27. Takeuchi, T., Kitagawa, H., Imagawa, T. and Uehara, M. 1998. Proliferation and cellular kinetics of villous epithelial cells and M cells in the chicken caecum. J. Anat. 193: 233-239.

28. Takeuchi, T., Kitagawa, H., Imagawa, T. and Uehara, M. 1999. Apoptosis of villous epithelial cells and follicle-associated epithelial cells in chicken cecum. J. Vet. Med. Sci. 61: 149154.

29. Webb, P., Chanana, A. D., Cronkite, E. P., Laissue, J. A. and Joel, D. D. 1980. Comparison of DNA renewal in germ-free and conventional mice using $\left[{ }^{125} \mathrm{I}\right]$ iododeoxyuridine and $\left[{ }^{3} \mathrm{H}\right]$ thymidine. Cell Tissue Kinet. 13: 227-237. 